\title{
Exploiting the Aromatic Chameleon Character of Fulvenes for Computational Design of Baird-Aromatic Triplet Ground State Compounds
}

Sangeeta Yadav, ${ }^{1}$ Ouissam El Bakouri, ${ }^{1}$ Kjell Jorner, ${ }^{1}$ Hui Tong, ${ }^{2}$ Christian Dahlstrand, ${ }^{2}$ Miquel Solà, ${ }^{3}$ and Henrik Ottosson ${ }^{1 *}$

${ }^{1}$ Department of Chemistry - Ångström Laboratory, Box 523, Uppsala University, 75120 Uppsala, Sweden, ${ }^{2}$ Department of Chemistry - BMC, Box 576, Uppsala University, 75123 Uppsala, Sweden, and ${ }^{3}$ Institut de Química Computacional i Catàlisi (IQCC), Universitat de Girona, c/ Maria Aurèlia Capmany 6, 17003 Girona, Catalonia, Spain.

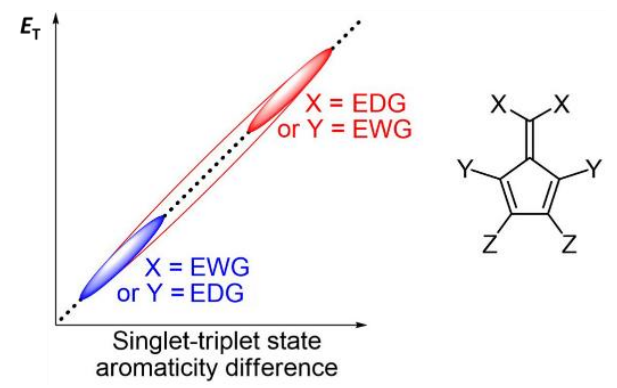

\begin{abstract}
Due to the reversal in electron counts for aromaticity and antiaromaticity in the closed-shell singlet state (normally ground state, $\left.\mathrm{S}_{0}\right)$ and lowest $\pi \pi^{*}$ triplet state $\left(\mathrm{T}_{1}\right.$ or $\left.\mathrm{T}_{0}\right)$, as given by Hückel's and Baird's rules, respectively, fulvenes are influenced by their substituents in the opposite manner in the $\mathrm{T}_{1}$ and $\mathrm{S}_{0}$ states. This effect is caused by a reversal in the dipole moment when going from $S_{0}$ to $T_{1}$ as fulvenes adapt to the difference in electron counts for aromaticity in various states; they are aromatic chameleons. Thus, a substituent pattern that enhances (reduces) fulvene aromaticity in $\mathrm{S}_{0}$ reduces (enhances) aromaticity in $\mathrm{T}_{1}$, allowing for rationalizations of the triplet state energies $\left(E_{\mathrm{T}}\right)$ of substituted fulvenes. Through quantum chemical calculations we now assess which substituents and
\end{abstract}


which positions on the pentafulvene core are the most powerful for designing compounds with low or inverted $E_{\mathrm{T}}$. As a means to increase the $\pi$-electron withdrawing capacity of cyano groups we found that protonation at the cyano $\mathrm{N}$ atoms of 6,6-dicyanopentafulvenes can be a route to on-demand formation of a fulvenium dication with a triplet ground state $\left(\mathrm{T}_{0}\right)$. The five-membered ring of this species is markedly Baird-aromatic, although less than the cyclopentadienyl cation known to have a Baird-aromatic $\mathrm{T}_{0}$ state.

\section{Introduction}

Pentafulvenes, or shortly fulvenes, are cross-conjugated compounds with a range of intriguing electronic and optical properties. ${ }^{[1]}$ They have, however, been overlooked for a long time,${ }^{[2]}$ likely due to their aptitude for oligomerization when not properly substituted and to the difficulty of selective substitution and functionalization. The parent fulvene is a weakly dipolar hydrocarbon in its singlet ground state $\left(\mathrm{S}_{0}\right)$, a result from the influence of a Hückel-aromatic zwitterionic resonance structure (Figure 1). ${ }^{[3-5]}$ Using Baird's rule on the reversal of the $(4 n+2) \pi$ - and $4 n \pi$-electron counts for aromaticity and antiaromaticity when going from the $\mathrm{S}_{0}$ state to the lowest $\pi \pi^{*}$ triplet state $\left(\mathrm{T}_{1}\right),{ }^{[6-13]}$ we earlier showed that the parent fulvene also exhibits a small dipole moment in its $\mathrm{T}_{1}$ state but in opposite direction to that in $\mathrm{S}_{0}{ }^{[14]}$ More explicitely, the five-membered ring (5MR) becomes influenced by $4 \pi$-electron Baird-aromaticity in the $T_{1}$ state through a zwitterionic resonance structure where the $\pi$-electron pair of the exocyclic double bond is pushed onto the methylene group and not into the ring as in the $\mathrm{S}_{0}$ state. ${ }^{[6]}$ Generally, fulvenes, including also tria- and heptafulvenes, can be labelled as aromatic chameleon compounds because of their abilities to adapt their electronic structures so as to be influenced by aromaticity in several electronic states. $^{[14]}$ 

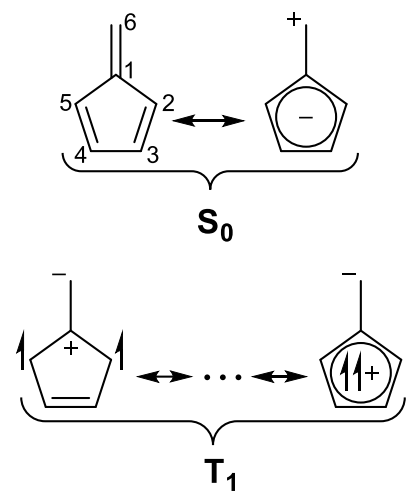

Figure 1: Aromatic resonance structures influencing the $S_{0}$ and $T_{1}$ states of pentafulvene resulting in an "aromatic chameleon" character.

The properties of substituted fulvenes have been the subject of numerous experimental and theoretical investigations. ${ }^{[1,15]}$ As a consequence of the opposite polarities of fulvenes in their $S_{0}$ and $T_{1}$ states exocyclic substituents have opposite effects on the aromaticities in these states, and this impacts on a series of properties. For example, exocyclic substituents that enhance the contribution of the zwitterionic resonance structure in $\mathrm{S}_{0}$ with a Hückel-aromatic $6 \pi$-electron $5 \mathrm{MR}^{[16]}$ will disfavor the zwitterionic resonance structure in $\mathrm{T}_{1}$ with a Baird-aromatic $4 \pi$-electron $5 \mathrm{MR}$ in $\mathrm{T}_{1} \cdot{ }^{[17]}$ Indeed, the difference between the $S_{0}$ and the $T_{1}$ state aromaticity was found to correlate with $E_{\mathrm{T}},{ }^{[18]}$ a relationship that can be useful for the design of functional molecules with tailored $E_{\mathrm{T}}$. Interestingly, a polarity reversal was also observed when going from the $S_{0}$ state to the lowest singlet excited state $\left(\mathrm{S}_{1}\right)$ of substituted fulvenes, ${ }^{[19]}$ and it has been found that the substituent effects of the lowest excited states of cyclopentadienes and siloles, being cross-hyperconjugated analogues of fulvenes, can be rationalized by this model as well. ${ }^{[18]}$ 


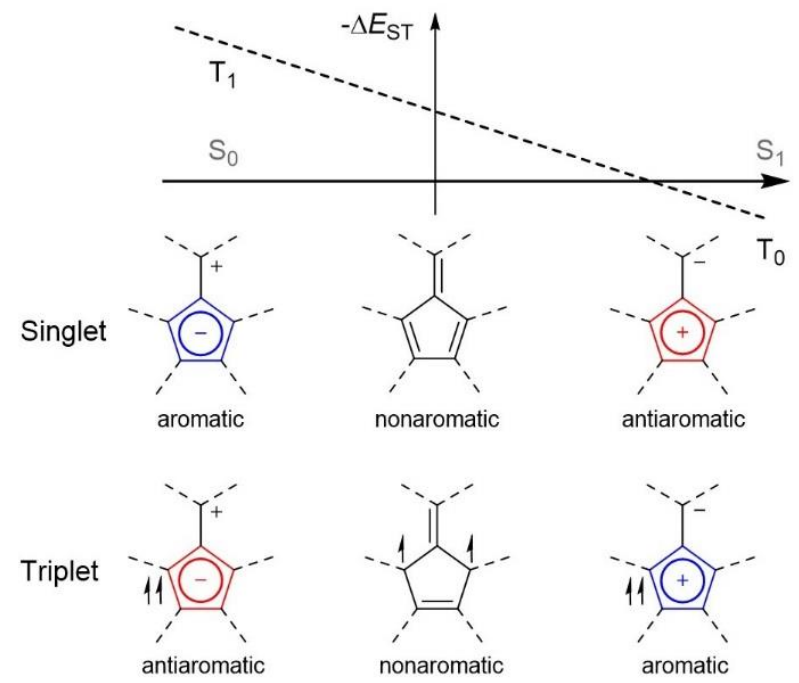

Figure 2: Schematic graph displaying the relative energies of the lowest singlet and triplet states as functions of the main resonance structure describing fulvenoid molecules, with blue structures being aromatic and red ones being antiaromatic.

Now, can the $E_{\mathrm{T}}$ of fulvenes be tuned to such extent that the triplet state becomes the ground state, i.e., a $\mathrm{T}_{0}$ state? Such a reversal in the order between the lowest singlet and triplet states would imply that the substituted fulvene is dominated by the resonance structure having a cationic 5MR and a negatively charged exocyclic C atom (Figure 2). Previously it was found that 1,2,3,4-tetrachloro-6,6-dicyanofulvene has a calculated $E_{\mathrm{T}}$ of $16.0 \mathrm{kcal} / \mathrm{mol}$, significantly lower than that of the parent fulvene $(36.8 \mathrm{kcal} / \mathrm{mol}){ }^{[17]}$ Since both the parent and the pentachloro substituted cyclopentadienyl cations $\left(\mathbf{C p}^{+}\right.$and $\mathbf{C p C l}^{+}$, respectively) have $\mathrm{T}_{0}$ states according to EPR and photoionization spectroscopy, ${ }^{[20-22]} \mathrm{a}$ fulvene with an electronic structure dominated by a resonance structure with a cationic 5MR is likely to have a $\mathrm{T}_{0}$ state. However, it is known from experiments that the order of the lowest two states of cyclopentadienyl cations depends strongly on the substituents; while $\mathbf{C p}^{+}$and $\mathbf{C p C l}^{+}$have $\mathrm{T}_{0}$ states, ${ }^{[20,21]}$ the pentaphenyl cyclopentadienyl cation has an $\mathrm{S}_{0}$ state. ${ }^{[18]}$ Indeed, the finding that $\mathbf{C p}^{+}$has a $\mathrm{T}_{0}$ state is in line with it being a non-disjoint diradical, a species with the triplet state below the open-shell singlet state. ${ }^{[23]}$ Several 
quantum chemical studies have also shown that $\mathbf{C} \mathbf{p}^{+}$is aromatic in its $\mathrm{T}_{0}$ state, ${ }^{[7,8,11,24,25]}$ in accordance with Baird's rule. ${ }^{[6]}$ In support of this last finding, the calculated aromatic stabilization energy of $\mathbf{C p}^{+}$in its $\mathrm{T}_{0}$ state is $20.9-23.2 \mathrm{kcal} / \mathrm{mol},{ }^{[7,25,26]}$ only slightly lower than the $22.1-28.8 \mathrm{kcal} / \mathrm{mol}$ for the cyclopentadienyl anion $\left(\mathbf{C p}^{-}\right)$in its $\mathrm{S}_{0}$ state. ${ }^{[27,28]} \mathrm{A} D_{5 \mathrm{~h}}$ symmetric structure observed experimentally is further in line with an aromatic character of the triplet state $\mathbf{C p}^{+}{ }^{[21]}$

Recently, several larger polycyclic and macrocyclic high-spin compounds which are influenced by Baird-aromaticity in their ground states have been generated, ${ }^{[29,30]}$ and a fulvalene with Baird-aromatic character in its $\mathrm{T}_{0}$ state was designed computationally. ${ }^{[31]}$ In our view it should be valuable to identify small triplet ground state compounds that can be synthesized easily, or alternatively, formed in one step from readily available precursor compounds. To probe if the $E_{\mathrm{T}}$ of fulvenes can be tuned to an inverted $E_{\mathrm{T}}$, we first performed quantum chemical calculations of the parent (1) and 48 disubstituted fulvenes (Figure 3). We probed which two positions are the most important in tuning $E_{\mathrm{T}}$; the two 6-positions $(\mathrm{X})$, the 2- and 5-positions (Y), or the 3- and 4-positions $(\mathrm{Z})$ ? The information from the disubstituted fulvenes provides the basis for design of further substituted fulvenes with very low and inverted $E_{\mathrm{T}}$. Finally, we explored computationally if a triplet ground state fulvenium cationic species can be generated by simple addition of an appropriate additive to a readily available and stable fulvene. Indeed, the calculations show that a fulvenium dication reached by diprotonation should have a $\mathrm{T}_{0}$ state and significant Baird-aromatic character.

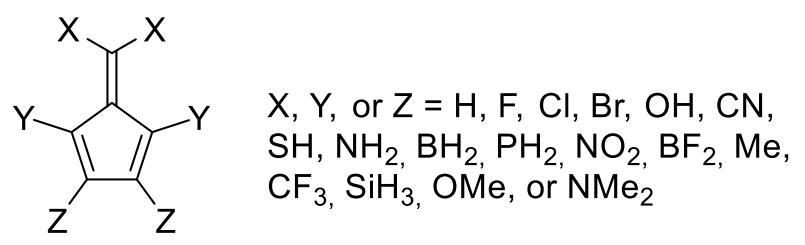

Figure 3: The parent fulvene and the set of disubstituted fulvenes, having either two X, Y or $\mathrm{Z}$ substituents, included in the present study. 


\section{Computational Methods}

Optimized geometries and energies of the substituted fulvenes of Figure 3 in $S_{0}$ and $T_{1}$ were obtained using the M06-2X functional. ${ }^{[32]}$ The bulk of these calculations was carried out with the $6-311+\mathrm{G}(\mathrm{d}, \mathrm{p})$ valence triple-zeta basis set of Pople and co-workers, ${ }^{[33]}$ but for a limited set of fulvenes we also used the cc-pVTZ valence triple-zeta basis set of Dunning. ${ }^{[34]}$ The nature of the optimized structure (minimum or saddle point) was probed through frequency calculations at the same level. All DFT calculations were performed using Gaussian 16 revision B.01. ${ }^{[35]}$ The DFT calculations of the $\mathrm{T}_{1}$ states were performed with the unrestricted Kohn-Sham formalism. To place the results of the (U)M06-2X calculations on a more firm ground we also examined the $E_{\mathrm{T}}$ of a few selected fulvenes through calculations with the G4 composite $\operatorname{method}^{[36]}$ and through state-avareged CASPT2 calculations with three states using the atomic natural orbital (ANO-RCC-VDZP) basis set with a contraction $[\mathrm{C}, \mathrm{N}, \mathrm{O}, \mathrm{F} / 3 \mathrm{~s} 2 \mathrm{p} 1 \mathrm{~d}, \mathrm{~S} / 4 \mathrm{~s} 3 \mathrm{p} 1 \mathrm{~d}, \mathrm{H} / 2 \mathrm{~s} 1 \mathrm{p}] .^{[37-39]}$ These latter calculations were carried out with the Molcas 8 and OpenMolcas packages. ${ }^{[39]}$

With regard to aromaticity, the magnitude is normally evaluated in terms of structural, magnetic, and energetic criteria. ${ }^{[40,41]}$ In analogy with the earlier study of monoand disubstituted fulvenes in their $\mathrm{S}_{0}$ states by Krygowski and co-workers, ${ }^{[42,14]}$ we used three readily accessible quantitative measures of aromaticity; the nucleus independent chemical shift (NICS) ${ }^{[43-46]}$ the harmonic oscillator model of aromaticity (HOMA) ${ }^{[47-48,49]}$ indices, and the aromatic fluctuation index (FLU). ${ }^{[50]}$ To analyze the ring-currents, ACID plots have been computed at the M06-2X/6-311+G(d,p) level. ${ }^{[51]}$ NICS values, taken as the negative of the out-of-plane of component of the NMR shielding tensors, were calculated using the gauge independent atomic orbital (GIAO) method ${ }^{[52]}$ at the GIAO-(U)M06-2X/6$311+\mathrm{G}(\mathrm{d}, \mathrm{p})$ level $1.0 \AA$ A above the ring centers $\left(\mathrm{NICS}(1){ }_{\mathrm{zz}}\right) .{ }^{[53]}$ For a few fulvenes, NICS-Z scans were performed as reported by Stanger, scanning from the ring centers to $5 \AA$ above the ring planes with increments of $0.1 \AA \AA^{[54,55]} \mathrm{HOMA}$ is a geometry based indicator of 
aromaticity, and takes a value of 1.0 for a perfectly aromatic system with all bond lengths equal to an ideal value (1.388 $\AA$ for CC bonds). ${ }^{[47-49]}$ Gradually more negative NICS values, as well as HOMA values that approach 1.0, indicate higher aromaticity of the rings.

FLU was calculated at the M06-2X/6-311+G(d,p) level of theory and was computed using delocalization indices, $\delta(\mathrm{A}, \mathrm{B}),{ }^{[56]}$ with the expression:

$$
F L U(\mathcal{A})=\frac{1}{N} \sum_{i=1}^{N}\left[\left(\frac{V\left(A_{i}\right)}{V\left(A_{i-1}\right)}\right)^{\alpha}\left(\frac{\delta\left(A_{i}, A_{i-1}\right)-\delta_{r e f}\left(A_{i}, A_{i-1}\right)}{\delta_{r e f}\left(A_{i}, A_{i-1}\right)}\right)\right]^{2}
$$

where $\mathrm{A}_{0} \equiv \mathrm{A}_{\mathrm{N}}$ and the string $\mathcal{A}=\left\{A_{1}, A_{2}, \ldots, A_{N}\right\}$ contains the ordered elements according to the connectivity of the $\mathrm{N}$ atoms in a ring or in a chosen circuit (FLU can be calculated for any arbitrary circuit in a given molecule). $\mathrm{V}(\mathrm{A})$ is defined as:

$$
V\left(A_{i}\right)=\sum_{A_{j} \neq A_{i}} \delta\left(A_{i}, A_{j}\right)
$$

and $\alpha$ is a simple function to make sure that the first term is always greater or equal to 1 . The FLU index was obtained with the ESI program. ${ }^{[57]}$ The delocalization indices of Eq. 1 were calculated using the overlaps between occupied molecular orbitals in the atomic basins generated by the AIMAll program. ${ }^{[58]}$ The $\delta_{r e f}(C, C)$ reference value of 1.389 e used for $\mathrm{C}-\mathrm{C}$ bonds in FLU calculations corresponds to the $\delta(C, C)$ of benzene computed at the M06-2X/6-311+G(d,p) level of theory. FLU is close to 0 in aromatic species, and differs from it in non-aromatic ones. As an indicator of Hückel (low values) or Baird (high values) aromatic character, we use the $\gamma$ descriptor defined as the absolute value of the $\Delta$ FLU $\alpha \beta / F L U$ ratio. ${ }^{[59]}$ To compute FLU $\alpha$ and FLU $U_{\beta}$, the same Eq. (1) was used but now considering only the $\alpha$ or $\beta$ molecular spin orbitals and taking the $\delta_{r e f}(C, C)$ reference value in Eq. (1) as half the reference value used for non-spin split FLU calculations. 


\section{Results and Discussion}

An important first question is if the planar $T_{1}$ state structures always correspond to the lowest minimum in the $T_{1}$ state of substituted fulvenes or if there can be fulvenes with the optimal $\mathrm{T}_{1}$ state structures having the $\mathrm{CX}_{2}$ plane twisted perpendicularly to the plane of the five-membered ring (5MR)? To resolve this issue we examined how the lowest two triplet states $\left(T_{1}\right.$ and $\left.T_{2}\right)$ vary in energy with rotation about the exocyclic $C=C$ bond in three fulvenes (Figure 4); the parent fulvene (1), one with high $E_{\mathrm{T}}(\mathbf{2})$ and one with low $E_{\mathrm{T}}(\mathbf{3})$. We subsequently explored the substituent effects on the $T_{1}$ energies of the various disubstituted fulvenes of Figure 3. Based on the information gained we design fulvenes and fulvenium dications with $\mathrm{T}_{0}$ states.

Optimal triplet state structures of fulvenes: Previously, we revealed a good agreement between the $E_{\mathrm{T}}$ of substituted fulvenes at their planar structures calculated with (U)M06-2X and those calculated with CASPT2 at (U)M06-2X geometries. ${ }^{[17]}$ A maximum deviation of $4.2 \mathrm{kcal} / \mathrm{mol}$ was found, yet, to further probe the quality of the (U)M06-2X computations we now performed state-averaged CASPT2/ANO-RCC-VDZP geometry optimizations in the $S_{0}, T_{1}$ and $T_{2}$ states of three fulvenes $\mathbf{1}-\mathbf{3}(\mathrm{X}=\mathrm{H}, \mathrm{F}$, and CN; Table 1 and Figure 4). These calculations were performed with an active space of eight electrons in eight orbitals for $\mathbf{1}$ and $\mathbf{2}$, and ten electrons in ten orbitals for $\mathbf{3}$. For the planar structures of the three fulvenes the largest difference in the $\mathrm{T}_{1}$ state energies $\left(E_{\mathrm{T}}\right)$ between CASPT2 and (U)M06-2X is $2.3 \mathrm{kcal} / \mathrm{mol}$ (Table 1 ). Moreover, CASPT2 geometry optimization brings no substantial change in the $E_{\mathrm{T}}$ because the CASPT2 geometries of the planar ${ }^{3} \mathrm{~B}_{2}$ state $\left(\mathrm{T}_{1}\right.$ state) resemble the corresponding UM06-2X geometries (Figure 4). 
Table 1: Relative energy (kcal/mol) of the $T_{1}$ and $T_{2}$ states calculated for 6,6-disubstituted fulvenes $(\mathrm{X}=\mathrm{H}(\mathbf{1}), \mathrm{F}(\mathbf{2})$, and $\mathrm{CN}(\mathbf{3}))$ constrained to their planar $\left(\omega=0^{\circ}\right)$ and the perpendicularly twisted $\left(\omega=90^{\circ}\right)$ conformations at $C_{2 \mathrm{v}}$ symmetry. Geometries were optimized at the (U)M06-2X and CASPT2 levels of theory.

\begin{tabular}{cccccc}
\hline $\mathrm{X}$ & $\omega$ & $\begin{array}{c}\text { Electronic } \\
\text { State }\end{array}$ & $\begin{array}{c}\text { M06-2X/ } \\
\text { cc-pVTZ }\end{array}$ & $\begin{array}{c}\text { active } \\
\text { space }\end{array}$ & $\begin{array}{c}\text { CASPT2/ANO-RCC- } \\
\text { VDZP }\end{array}$ \\
\hline & 0 & ${ }^{3} \mathrm{~B}_{2}$ & $39.3\left(38.9^{a}\right)$ & & 40.3 \\
$\mathrm{H}$ & 0 & ${ }^{3} \mathrm{~A}_{1}$ & - & 61.6 \\
& 90 & ${ }^{3} \mathrm{~B}_{1}$ & $52.7\left(52.1^{a}\right)$ & & 56.2 \\
& 90 & ${ }^{3} \mathrm{~A}_{2}$ & - & $58.3^{b}$ \\
\hline & 0 & ${ }^{3} \mathrm{~B}_{2}$ & $45.1\left(44.2^{a}\right)$ & & 44.4 \\
$\mathrm{~F}$ & 0 & ${ }^{3} \mathrm{~A}_{1}$ & - & 66.7 \\
& 90 & ${ }^{3} \mathrm{~B}_{1}$ & $60.5\left(58.8^{a}\right)$ & & 65.7 \\
& 90 & ${ }^{3} \mathrm{~A}_{2}$ & - & & $62.2^{b}$ \\
\hline & 0 & ${ }^{3} \mathrm{~B}_{2}$ & $26.0\left(25.8^{a}\right)$ & & 28.3 \\
$\mathrm{CN}$ & 0 & ${ }^{3} \mathrm{~A}_{1}$ & - & 10 in 10 & 46.7 \\
& 90 & ${ }^{3} \mathrm{~B}_{1}$ & $45.6\left(44.8^{a}\right)$ & & 45.7 \\
& 90 & ${ }^{3} \mathrm{~A}_{2}$ & - & & $47.4^{b}$
\end{tabular}

${ }^{a}$ Performed with the $6-311+\mathrm{G}(\mathrm{d}, \mathrm{p})$ basis set. ${ }^{b}$ Single point calculation at the $\mathrm{T}_{1}$ optimized geometry. The planar and the perpendicularly twisted conformations adopt $C_{2 \mathrm{v}}$ symmetry. The electronic states ${ }^{3} \mathrm{~B}_{2}$ and ${ }^{3} \mathrm{~A}_{1}$ at planar structures transform via ${ }^{3} \mathrm{~B}$ and ${ }^{3} \mathrm{~A}$ to ${ }^{3} \mathrm{~B}_{1}$ and ${ }^{3} \mathrm{~A}_{2}$, respectively, at the twisted structure. 

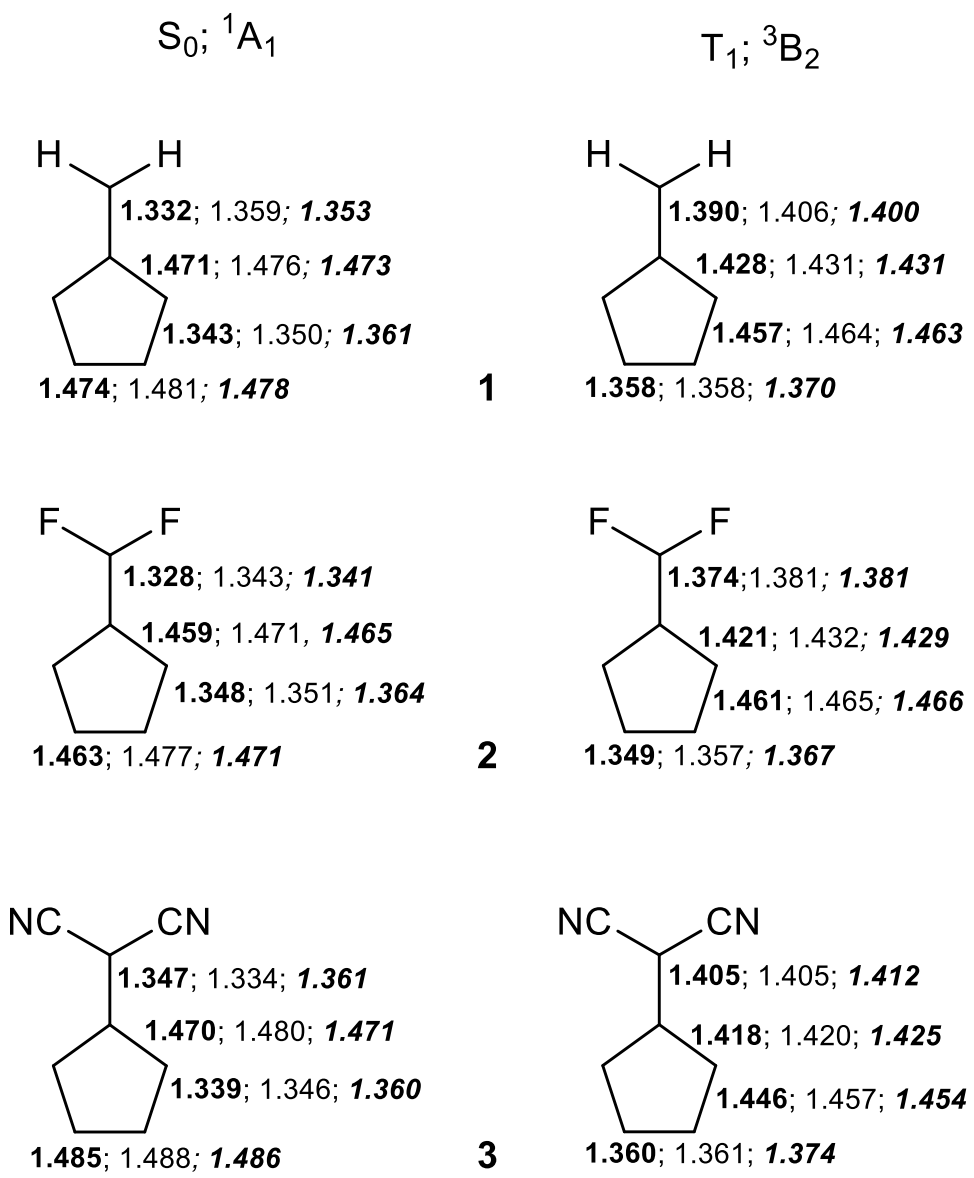

Figure 4: Comparison between the (U)M06-2X/cc-pVTZ (bold), CASSCF/ANOS-RCCVDZP (normal print) and CASPT2/ANOS-RCC-VDZP (bold italics) optimized geometries at the planar $\mathrm{S}_{0}$ and $\mathrm{T}_{1}$ structures of $C_{2 \mathrm{v}}$ symmetry.

Rotation about the exocyclic $\mathrm{C}=\mathrm{C}$ double bond should be more facile in $\mathrm{T}_{1}$ than in $\mathrm{S}_{0}$ as the exocyclic $\mathrm{CC}$ bond is elongated upon excitation. A fulvene with the $\mathrm{CX}_{2}$ moiety oriented perpendicularly to the $5 \mathrm{MR}$ could even be lower in energy than the planar $\mathrm{T}_{1}$ state structure. Yet, CASPT2 calculations reveal that for each of $\mathbf{1}-\mathbf{3}$, the planar structures of the $\mathrm{T}_{1}$ state $\left(1^{3} \mathrm{~B}\right.$; primarily a HOMO to LUMO excitation) are more stable than the twisted ones (Table 1). On the other hand, for $\mathbf{1}$ and $\mathbf{2}$ the $\mathrm{T}_{2}$ state $\left(1^{3} \mathrm{~A}\right.$; primarily a HOMO-1 to LUMO excitation) prefers the twisted structure over the planar one, while the $T_{2}$ surface is shallow for 3. At planar structures the $\mathrm{T}_{2}$ states of the three fulvenes are $18-22 \mathrm{kcal} / \mathrm{mol}$ above the $T_{1}$ states, whereas at the perpendicularly twisted structures the $T_{1}$ and $T_{2}$ states 
are isoenergetic. Accordingly, the $\mathrm{T}_{1}$ and $\mathrm{T}_{2}$ states vary as shown in Figure 5. Since the energy of the $1^{3} \mathrm{~B}$ state increases upon $\mathrm{C}=\mathrm{C}$ bond rotation it is justified to perform the analysis of the different fulvenes at structures which are close to planarity, both in $\mathrm{T}_{1}$ and $\mathrm{S}_{0}$. Moreover, the energies of the two $\mathrm{T}_{1}$ state structures (both the planar and the twisted ones) calculated with (U)M06-2X resemble closely those of CASPT2 (maximum absolute deviation is $5.2 \mathrm{kcal} / \mathrm{mol})$, justifying the choice of (U)M06-2X for the bulk of the computations.

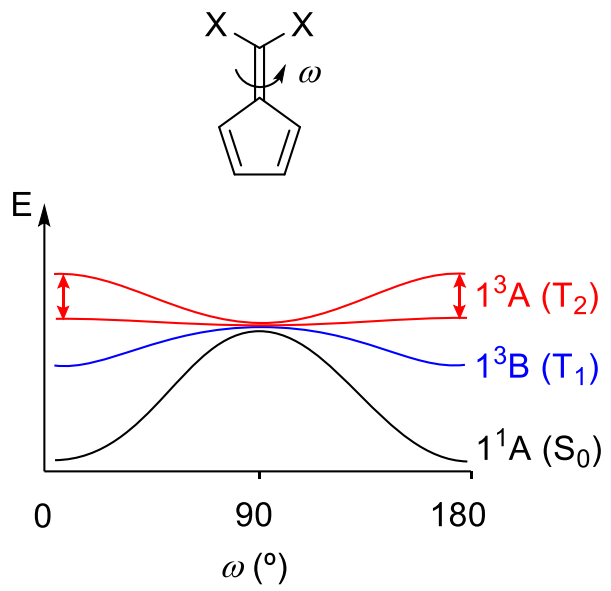

Figure 5: Schematic drawing of the $S_{0}, T_{1}$ and $T_{2}$ potential energy surfaces of fulvene as a function of C-C-C-X dihedral angle $\omega$. The exact order of the three states at $\omega=90^{\circ}$ varies with X (see Table 1).

Connection between the $S_{0}-T_{1}$ aromaticity difference and $E_{T}$ : The changes in aromaticity when going from $\mathrm{S}_{0}$ to $\mathrm{T}_{1}$ were determined by $\Delta \mathrm{NICS}(1)_{\mathrm{zz}, \mathrm{ST}}=\mathrm{NICS}\left(1 ; \mathrm{T}_{1}\right)_{\mathrm{zz}}-$ $\operatorname{NICS}\left(1 ; \mathrm{S}_{0}\right)_{\mathrm{zz}}$ and $\Delta \mathrm{HOMA}_{\mathrm{ST}}=\operatorname{HOMA}\left(\mathrm{T}_{1}\right)-\operatorname{HOMA}\left(\mathrm{S}_{0}\right)$. Significantly negative NICS values, as well as HOMA values approaching 1.0, indicate high aromaticity of the 5MRs. Accordingly, $\Delta \mathrm{NICS}(1)_{\mathrm{zz}, \mathrm{ST}}<0$ and $\Delta \mathrm{HOMA}_{\mathrm{ST}}>0$ reveal aromaticity gains as one goes from the $\mathrm{S}_{0}$ to the $\mathrm{T}_{1}$ state. Conversely, $\Delta \mathrm{NICS}(1)_{\mathrm{zz}, \mathrm{ST}}>0$ and $\Delta \mathrm{HOMA}_{\mathrm{ST}}<0$ indicate aromaticity loss upon excitation. An increased influence of $T_{1}$ aromaticity of a substituted fulvene when compared to that of $\mathbf{1}$ should be accompanied by a stabilization of the $\mathrm{T}_{1}$ state 
and a lower $E_{\mathrm{T}}$. An increased influence of aromaticity in the $\mathrm{S}_{0}$ state of a substituted fulvene when compared to 1 has the opposite effect on $E_{\mathrm{T}}$. The $\Delta \mathrm{NICS}(1)_{\mathrm{zz}, \mathrm{ST}}$ varies by $\sim 90 \mathrm{ppm}$ at the same time as $E_{\mathrm{T}}$ varies by more than $35 \mathrm{kcal} / \mathrm{mol}$ (Figure 6). Indeed, a linear correlation between $E_{\mathrm{T}}$ and $\triangle \mathrm{NICS}(1)_{\mathrm{zz}, \mathrm{ST}}$ is found $\left(\mathrm{R}^{2}=0.880\right)$, also when going to fulvenes with low $E_{\mathrm{T}}$ (below $\sim 20 \mathrm{kcal} / \mathrm{mol}$ ). This extends our earlier similar observation for a smaller set of 6,6-disubstituted fulvenes with higher $E_{\mathrm{T}}{ }^{[18]}$

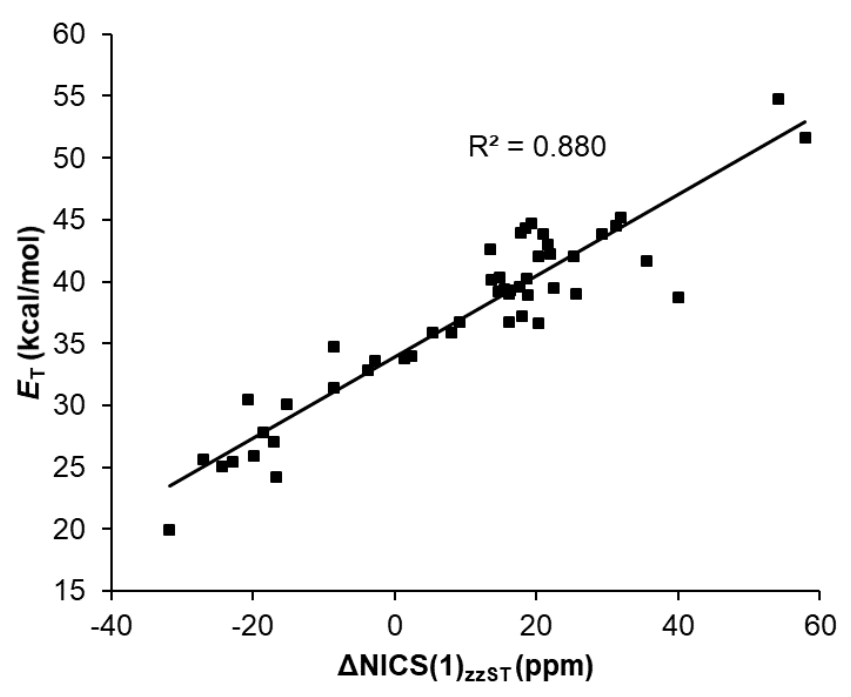

Figure 6: Dependence of $E_{\mathrm{T}}$ on $\triangle \mathrm{NICS}(1)_{\mathrm{zz}, \mathrm{ST}}$ for the parent fulvene and 48 disubstituted fulvenes with substitution at the $\mathrm{X}, \mathrm{Y}$ or $\mathrm{Z}$ positions. Squared correlation coefficient $\mathrm{R}^{2}=$ 0.880. Computations at M06-2X/6-311+G(d,p) level.

In contrast, a poor correlation is observed between $E_{\mathrm{T}}$ and $\Delta \mathrm{HOMA}\left(\mathrm{R}^{2}=0.523\right.$, Figure 7). Better correlations are found for the subsets of X- and Y-substituted fulvenes, particularly for the $\mathrm{X}$-substituted ones $\left(\mathrm{R}^{2}=0.949\right.$ and 0.601 , respectively, Figure S2A and $\mathrm{S} 2 \mathrm{~B})$, whereas there is no correlation for the Z-substituted fulvenes $\left(\mathrm{R}^{2}=0.006\right.$, Figure $\mathrm{S} 2 \mathrm{C})$. The lack of correlation for the Z-substituted fulvenes is in part due to a larger steric repulsion between the two $\mathrm{Z}$ substituents in the $\mathrm{T}_{1}$ state than in the $\mathrm{S}_{0}$ state, a feature that stems from a marked influence by a $\mathrm{T}_{1}$ state resonance structure with a formal double bond 
between the two Z-substituted carbon atoms (Figure 1). Additionally, the lack of correlation is also related to HOMO and LUMO since these orbitals have larger lobes at C2, C5 and C6 than at $\mathrm{C} 3$ and $\mathrm{C} 4$ (Figure 8).

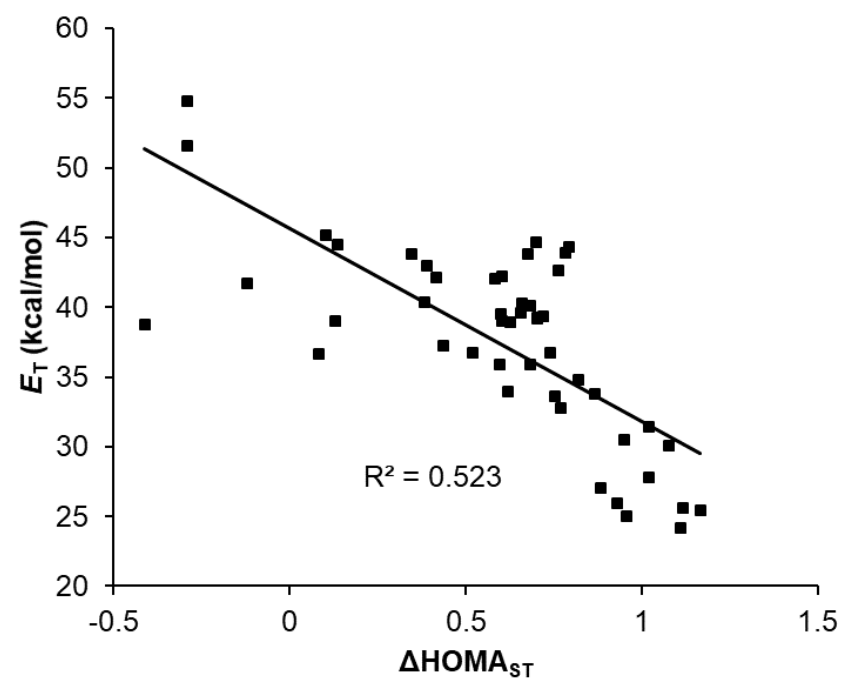

Figure 7: Dependence of $E_{\mathrm{T}}$ on $\triangle \mathrm{HOMA}_{\mathrm{ST}}\left(\mathrm{R}^{2}=0.523\right)$ for fulvene and disubstituted fulvenes with substitution at the $\mathrm{X}, \mathrm{Y}$ or $\mathrm{Z}$ positions.

Substituents influence the $S_{0}$ state as well as the $T_{1}$ state by either increasing or decreasing the zwitterionic aromatic character, and in opposite directions in the two states. However, at what positions do the substituents have the largest influence? And which type of substituents should be placed at these positions so as to achieve low or inverted $E_{\mathrm{T}}$ ? In accordance with the observations made just above, the variations in $E_{\mathrm{T}}, \Delta \mathrm{NICS}(1)_{\mathrm{zz}, \mathrm{ST}}$ and $\triangle$ HOMAst $_{\text {for }}$ the $\mathrm{X}$ - or Y-substituted fulvenes are considerably larger than for the Zsubstituted fulvenes; the variations in $E_{\mathrm{T}}$ are $30.6(\mathrm{X}), 23.1(\mathrm{Y})$ and $7.9(\mathrm{Z}) \mathrm{kcal} / \mathrm{mol}$, those in $\triangle \mathrm{NICS}(1)_{\mathrm{zz}, \mathrm{ST}}$ are $55.9(\mathrm{X}), 48.1(\mathrm{Y})$ and $6.6(\mathrm{Z}) \mathrm{ppm}$, and those in $\Delta \mathrm{HOMA}_{\mathrm{ST}}$ are 1.5 $(\mathrm{X}), 1.5(\mathrm{Y})$ and $0.2(\mathrm{Z})$. Noteworthy, a certain substituent has clearly opposite effects on $E_{\mathrm{T}}$ when attached at different positions (Table 2). For example, when two amino groups are moved from the $\mathrm{X}$ to the $\mathrm{Y}$ positions (fulvene $6 \mathrm{vs.}$ 7) the $E_{\mathrm{T}}$ changes from 54.8 to 19.9 $\mathrm{kcal} / \mathrm{mol}$. Fulvenes with small $E_{\mathrm{T}}$ are generally obtained with electron-donating groups 
(EDGs) as $\mathrm{Y}$ or with electron-withdrawing groups (EWGs) as $\mathrm{X}$. This is consistent with their aromatic chameleon feature (Figure 1) because with EDGs as $Y$ the cationic charge in the $5 \mathrm{MR}$ of the $\mathrm{T}_{1}$ state can be delocalized onto the substituents while with EWGs as $\mathrm{X}$ the negative charge on the exocyclic $\mathrm{C}$ atom can be delocalized to these groups. In line with this, when the two amino groups are moved from the X-to the Y-positions (fulvenes $6 v s$. 7) there is a simultaneous change in aromaticity in both the $\mathrm{S}_{0}$ and $\mathrm{T}_{1}$ states; the NICS $\left(1, \mathrm{~S}_{0}\right)_{\mathrm{zz}}$ value changes by $+29.2 \mathrm{ppm}$ to less aromatic while the $\operatorname{NICS}\left(1, \mathrm{~T}_{1}\right)_{\mathrm{zz}}$ value changes by -27.4 ppm to more aromatic (Table 2). Similar differences are found in the HOMA values of the two compounds in $S_{0}$ and $T_{1}$, respectively.

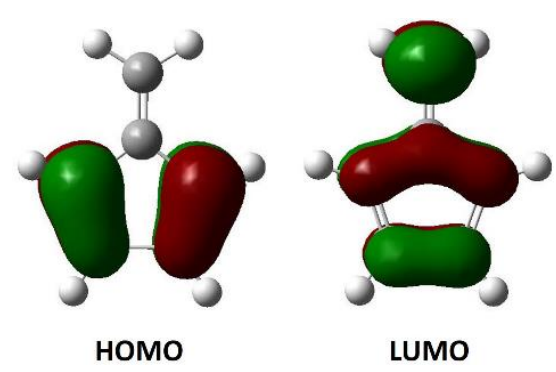

Figure 8: HOMO and LUMO of parent fulvene at (U)M06-2X/6-311+G(d,p) level.

Table 2: Calculated $E_{\mathrm{T}}(\mathrm{kcal} / \mathrm{mol}), \operatorname{NICS}(1)_{\mathrm{zz}}(\mathrm{ppm})$, and HOMA for fulvene (1) and disubstituted derivatives $(\mathbf{1}, \mathbf{3}-\mathbf{1 4})$ in the $S_{0}$ and $T_{1}$ states.

\begin{tabular}{lccccc}
\hline \multirow{2}{*}{ Fulvene } & \multirow{2}{*}{$E_{\mathrm{T}}$} & \multicolumn{2}{c}{$\mathrm{NICS}(1)_{\mathrm{zz}}$} & \multicolumn{2}{c}{$\mathrm{HOMA}$} \\
\cline { 3 - 6 } & & $\mathrm{S}_{0}$ & $\mathrm{~T}_{1}$ & $\mathrm{~S}_{0}$ & $\mathrm{~T}_{1}$ \\
\hline $\mathbf{1}, \mathrm{X}=\mathrm{H}$ & 39.0 & -5.6 & 5.0 & -0.3 & 0.3 \\
$\mathbf{3}, \mathrm{X}=\mathrm{CN}$ & 25.9 & 9.2 & -1.4 & -0.5 & 0.5 \\
$\mathbf{4}, \mathrm{Y}=\mathrm{CN}$ & 36.6 & -7.2 & 6.0 & -0.1 & 0.0 \\
$\mathbf{5}, \mathrm{Z}=\mathrm{CN}$ & 39.5 & -7.7 & 7.0 & -0.2 & 0.4 \\
$\mathbf{6}, \mathrm{X}=\mathrm{NH}_{2}$ & 54.7 & -18.9 & 16.4 & 0.4 & 0.2 \\
$\mathbf{7}, \mathrm{Y}=\mathrm{NH}_{2}$ & 19.9 & 10.3 & -11.0 & -0.6 & 0.5 \\
$\mathbf{8}, \mathrm{Z}=\mathrm{NH}_{2}$ & 42.7 & -4.0 & 5.6 & -0.3 & 0.4 \\
\hline
\end{tabular}




\begin{tabular}{lccccc}
\hline $\mathbf{9}, \mathrm{X}=\mathrm{OH}$ & 45.2 & -11.4 & 9.1 & 0.1 & 0.2 \\
$\mathbf{1 0}, \mathrm{Y}=\mathrm{OH}$ & 27.8 & 6.2 & -6.3 & -0.5 & 0.5 \\
$\mathbf{1 1}, \mathrm{Z}=\mathrm{OH}$ & 44.7 & -4.5 & 10.2 & -0.4 & 0.3 \\
$\mathbf{1 2}, \mathrm{X}=\mathrm{CF}_{3}$ & 30.1 & 5.6 & -4.0 & -0.7 & 0.4 \\
$\mathbf{1 3}, \mathrm{Y}=\mathrm{CF}_{3}$ & 43.0 & -5.5 & 10.5 & -0.2 & 0.2 \\
$\mathbf{1 4}, \mathrm{Z}=\mathrm{CF}_{3}$ & 42.0 & -6.1 & 8.2 & -0.3 & 0.3 \\
\hline
\end{tabular}

Triplet ground state fulvenes: As noted above 2,3,4,5-tetrachloro-6,6dicyanofulvene (15) has a calculated $E_{\mathrm{T}}$ of $\sim 16 \mathrm{kcal} / \mathrm{mol} .{ }^{[17]}$ Using the relationship between the electronic substituent effects, the $\mathrm{S}_{0}$ and $\mathrm{T}_{1}$ aromaticities, and $E_{\mathrm{T}}$ we can now design fulvenes with much smaller and even inverted $E_{\mathrm{T}}$, i.e., $E_{\mathrm{T}}<0 \mathrm{kcal} / \mathrm{mol}$ (fulvenes with $\mathrm{T}_{0}$ states). The combination of EWGs as $\mathrm{X}\left(\mathrm{CN}, \mathrm{NO}_{2}\right.$, or $\left.\mathrm{CF}_{3}\right)$ with EDGs as $\mathrm{Y}\left(\mathrm{NH}_{2}, \mathrm{NMe}_{2}\right.$, $\mathrm{OH}, \mathrm{OMe}$, or $\mathrm{SH})$ brings down $E_{\mathrm{T}}$ considerably $\left(E_{\mathrm{T}} \leq 12 \mathrm{kcal} / \mathrm{mol}\right.$ with M06-2X, Table 3$)$, and the $E_{\mathrm{T}}$ of $\mathbf{1 8}$ is even inverted at M06-2X level. To check these results, the $E_{\mathrm{T}}$ were also computed at CASPT2 level. At this level the triplet states are generally slightly less stabilized relative to the singlet states than what is the case at M06-2X level.

Fulvene 18 has the strongest EDG as $\mathrm{Y}$, and the two cyano groups as $\mathrm{X}$ are in conjugation with the exocyclic double bond, in contrast to the two nitro groups in $\mathbf{1 6}$ which are twisted relative to the $5 \mathrm{MR}$ in both the $\mathrm{S}_{0}$ and $\mathrm{T}_{1}$ states. With thermal energy corrections from M06-2X calculations, the $\Delta G_{\mathrm{T}}$ at CASPT2 level is such that $\mathbf{1 8}$ at $298 \mathrm{~K}$ still has a $\mathrm{T}_{0}$ state. In further support, calculations with the high-level G4 composite method ${ }^{[36]}$ gives a $\Delta G_{\mathrm{T}}$ for 18 of $-1.3 \mathrm{kcal} / \mathrm{mol}$, confirming $\mathbf{1 8}$ as a triplet ground state species. Finally, the impact of the positions of the substituent is revealed by exchanging the positions of the cyano and amino groups in $\mathbf{1 8}$, leading to fulvene $\mathbf{2 3}$, a species with a $\Delta G_{\mathrm{T}}$ of $53.0 \mathrm{kcal} / \mathrm{mol}$ at M06-2X level. 
Table 3: Calculated $E_{\mathrm{T}}$ and $\Delta G_{\mathrm{T}}(\mathrm{kcal} / \mathrm{mol})$ for tetrasubstituted fulvene derivatives. ${ }^{a}$

\begin{tabular}{cccccc}
\hline \multirow{2}{*}{ Fulvene } & \multirow{2}{*}{$\mathrm{X}$} & $\mathrm{Y}$ & Symmetry & \multicolumn{2}{c}{$E_{\mathrm{T}}\left(\Delta G_{\mathrm{T}}\right)$} \\
\cline { 4 - 6 } & & & $\mathrm{S}_{0} ; \mathrm{T}_{1}$ & $(\mathrm{U}) \mathrm{M} 06-2 \mathrm{X}$ & $\mathrm{CASPT}^{b}$ \\
\hline $\mathbf{1 6}$ & $\mathrm{NO}_{2}$ & $\mathrm{NH}_{2}$ & $C_{2} ; C_{2}$ & $6.0(4.3)$ & $10.3(9.2)$ \\
$\mathbf{1 7}$ & $\mathrm{CF}_{3}$ & $\mathrm{NH}_{2}$ & $C_{2} ; C_{2}$ & $0.5(-1.3)$ & $4.0(2.3)$ \\
$\mathbf{1 8}$ & $\mathrm{CN}$ & $\mathrm{NH}_{2}$ & $C_{\mathrm{s}} ; C_{2 \mathrm{v}}$ & $-3.5(-5.3)$ & $0.7(-1.1)$ \\
$\mathbf{1 9}$ & $\mathrm{CN}$ & $\mathrm{NMe}_{2}$ & $C_{2} ; C_{\mathrm{s}}$ & $5.0(4.1)$ & $10.7(9.9)$ \\
$\mathbf{2 0}$ & $\mathrm{CN}$ & $\mathrm{OH}$ & $C_{2 \mathrm{v}} ; C_{2 \mathrm{v}}$ & $10.7(10.0)$ & $14.4(13.7)$ \\
$\mathbf{2 1}$ & $\mathrm{CN}$ & $\mathrm{OMe}$ & $C_{2 \mathrm{v}} ; C_{2 \mathrm{v}}$ & $12.3(10.7)$ & $15.9(14.2)$ \\
$\mathbf{2 2}$ & $\mathrm{CN}$ & $\mathrm{SH}$ & $C_{2 \mathrm{v}} ; C_{2 \mathrm{v}}$ & $9.2(8.2)$ & $13.1(12.0)$ \\
$\mathbf{2 3}$ & $\mathrm{NH}_{2}$ & $\mathrm{CN}$ & $C_{2}, C_{2}$ & $56.1(53.0)$ & --
\end{tabular}

${ }^{a}$ The active space included five valence $\pi$ orbitals, the two highest occupied $\sigma$ orbitals and the corresponding virtual ones. The number of active electrons was set to fourteen. ${ }^{b}$ The $\Delta G_{\mathrm{T}}$ values at CASPT2 level include thermal energy corrections from M062X level calculations.

The computations suggest that a fulvene in its ground state can be strongly influenced by the resonance structure described by a cationic 5MR and a negatively charged exocyclic methylene position. It is therefore useful with a comparison of triplet state $\mathbf{1 8}$ with the triplet state of 1,3-diamino $\mathbf{C p}^{+}$, representing the $5 \mathrm{MR}$ of the limiting zwitterionic resonance structure of $\mathbf{1 8}$ in its $\mathrm{T}_{0}$ state. First, the charge distribution between the exocyclic dicyano methylene moiety and the $5 \mathrm{MR}$ including the two amino groups of $\mathrm{T}_{0}$ state $\mathbf{1 8}$ is not fully zwitterionic as the charge divisions between the two units are $-0.44 /+0.44$ e with NPA, $-0.33 /+0.33$ e with Hirschfeld, and $-0.41 /+0.41$ e with CHelpG. The charge on the $5 \mathrm{MR}$ of ${ }^{\mathbf{3}} \mathbf{1 , 3}$-diamino $\mathrm{Cp}^{+}$, excluding the $\mathrm{H}$ atom at the $\mathrm{C}$ atom in the 2-position, is $+0.77 \mathrm{e}$ with NPA, +0.91 e with Hirschfeld, and +0.81 e with $\mathrm{CHelpG}$, respectively. The total spin density further reveal a difference between the triplet state of $\mathbf{1 8}$ and that of $\mathbf{1 , 3 - d i a m i n o C} \mathbf{p}^{+}$ because the total spin density at the $5 \mathrm{MR}$ of $\mathbf{1 8}$, excluding the two amino groups, is $1.10 \mathrm{e}$ 


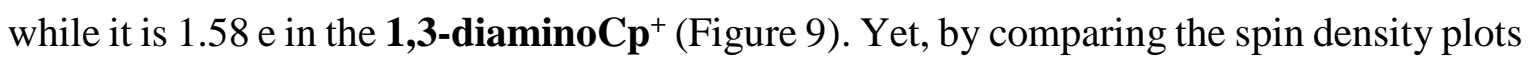
of 18 and 1,3-diaminoC $\mathbf{p}^{+}$, one still sees a strong resemblance between the two species.
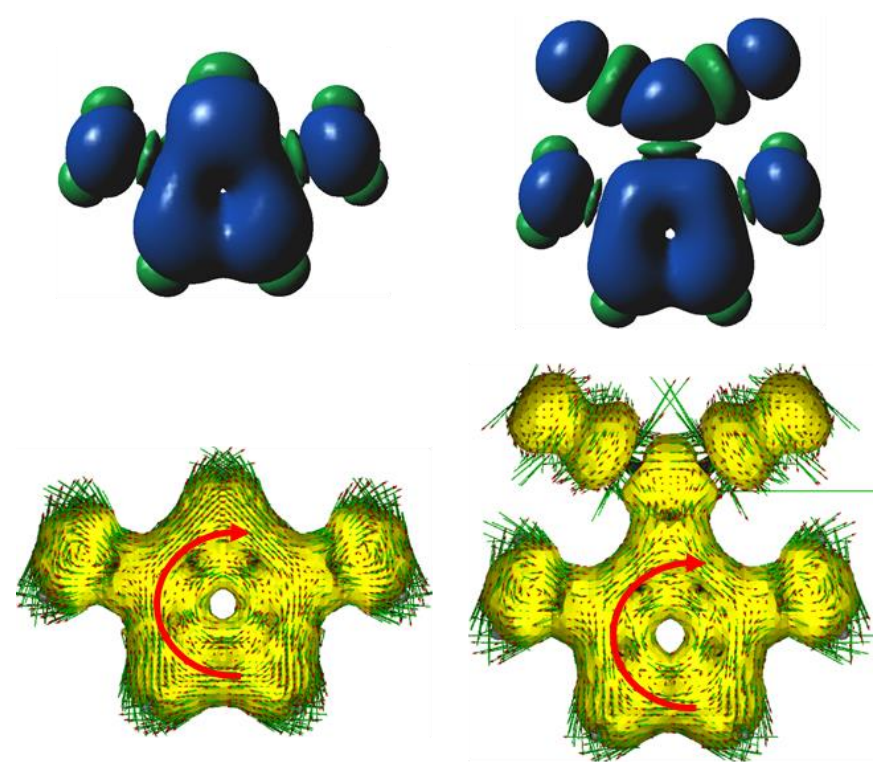

1,3-diaminoCp ${ }^{+}$

18

Figure 9: Spin density (above) and ACID (below) plots for ${ }^{\mathbf{3}} \mathbf{1 , 3 - d i a m i n o} \mathbf{C p}^{+}$and ${ }^{\mathbf{3}} \mathbf{1 8}$ computed at M06-2X/6-311+(d,p) level. Red arrows overlayed on the ACID plots to indicate the direction of the ring-currents.

With regard to the geometries the $\mathrm{CC}$ bond lengths of the 5MRs are rather similar in the triplet states of $\mathbf{1 8}$ and $\mathbf{1 , 3 - d i a m i n o C} \mathbf{p}^{+}$with the largest deviation being in one bond that differs in length by $0.03 \AA$ (see Figure S5). Noteworthy, the 1,3-diaminocyclopentadiene moiety in the triplet ground state fulvalene of Solel and Kozuch is influenced by Baird-aromaticity, ${ }^{[31]}$ and it resembles geometrically the $5 \mathrm{MR}$ of 18. Yet, a stark difference between $\mathbf{1 8}$ and 1,3-diaminoC $\mathbf{p}^{+}$is the order of the lowest singlet and triplet states because 1,3-diaminoC $\mathrm{p}^{+}$has an $\mathrm{S}_{0}$ state with $E_{\mathrm{T}}=28.5 \mathrm{kcal} / \mathrm{mol}$ and $\Delta G_{\mathrm{T}}=26.2 \mathrm{kcal} / \mathrm{mol}$. The cause for this difference is a much stronger $\pi$-conjugative interaction between the amino groups and the central $\mathrm{Cp}^{+}$ring in the singlet state of $\mathbf{1 , 3 - d i a m i n o C \mathbf { p } ^ { + }}$ than in $\mathbf{1 8}$ as revealed by C-N bond lengths of 1.313 and $1.390 \AA$, respectively (Figure S5). ${ }^{[60]}$ 
Although there is a stark difference in the order of the singlet and triplet states of $\mathbf{1 8}$ and 1,3-diamino $\mathbf{C p}^{+}$, the triplet states are similar and we further analyzed the extent of Baird-aromaticity of the two species. The aromatic characters of the triplet states for $\mathbf{1 8}$, 1,3-diaminoC $\mathbf{p}^{+}, \mathbf{1}$ and $\mathbf{C p}^{+}$have been assessed in terms of the FLU, ACID and NICS. We first calculated the $\Delta \mathrm{FLU}_{\alpha \beta}=\mathrm{FLU}_{\alpha}-\mathrm{FLU}_{\beta}$ and $\gamma=\left|\Delta \mathrm{FLU} \mathrm{U}_{\alpha \beta}\right| / \mathrm{FLU}$ which quantify the difference in FLU contributions due to $\alpha$ and $\beta$ electrons. A difference in FLU $\alpha$ and FLU $\beta$ is expected for Baird-aromatic compounds $\left(\Delta \mathrm{FLU}_{\alpha \beta} \neq 0\right)$, and we recently used this value to differentiate Hückel-aromatic from Baird-aromatic rings in Hückel-Baird aromatic hybrid molecules. ${ }^{[59]}$ Concerning the $\mathrm{T}_{0}$ state of 18, a FLU value of 0.0243 reveals a rather low Baird-aromatic character, with this character being somewhat more pronounced in ${ }^{\mathbf{3}} \mathbf{1 , 3}$ diaminoC $\mathbf{p}^{+}(0.0215)$. Also the $\gamma$ value shows that the triplet state Baird-aromaticity of $\mathbf{1 8}$ (2.303) is slightly lower than that of $\mathbf{1 , 3 - d i a m i n o C \mathbf { p } ^ { + }}$ (2.543). Still, the values demonstrate that the 5-MRs in the triplet states of both compounds are significantly Baird-aromatic. When comparing 18 with $\mathbf{1}$, a larger $\Delta F L U_{\alpha \beta}$ and $\gamma$ is detected for $\mathbf{1 8}$ (0.056 and 2.31, respectively) revealing that its Baird-aromatic character is more pronounced than that in the $\mathrm{T}_{1}$ state of $\mathbf{1}(\Delta \mathrm{FLU} \alpha \beta=0.022$ and $\gamma=1.36)$. For ${ }^{3} \mathbf{C p}^{+}$, the reference compound for triplet state Baird-aromaticity, the $\Delta \mathrm{FLU} \alpha \beta$ and $\gamma$ values are 0.038 and 4.48 , respectively. The spin density distribution is in line with this observation because the delocalization of spin onto the $\mathrm{NH}_{2}$ groups of $\mathbf{1 8}(0.68)$ is larger than in $\mathbf{1 , 3 - d i a m i n o C} \mathbf{p}^{+}(0.45)$, supporting a more pronounced triplet state (Baird-aromatic) cyclopentadienyl cationic character in the latter species.

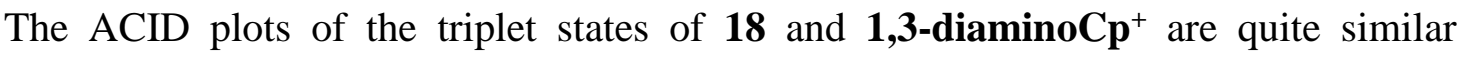
revealing clear diatropic currents (Figure 9). Moreover, the minimum values in the NICS-Z scans for $\mathbf{1 8}$ and 1,3-diaminoC $\mathbf{p}^{+}$is -12.5 and -12.1 ppm (Figure 10), respectively, revealing that both systems are approximately equally aromatic. These values are intermediate 
between the corresponding values of $\mathbf{1}$ and $\mathbf{C} \mathbf{p}^{+}$in their triplet states (-4.3 and -26.3 ppm, respectively). Summing up, the $5 \mathrm{MR}$ of $\mathbf{1 8}$ in its $\mathrm{T}_{0}$ state is nearly as Baird-aromatic as $\mathbf{1 , 3 -}$ diaminoC $\mathbf{p}^{+}$in its triplet state, yet, the $\mathrm{T}_{0}$ state of $\mathbf{C} \mathbf{p}^{+}$is significantly more Baird-aromatic.
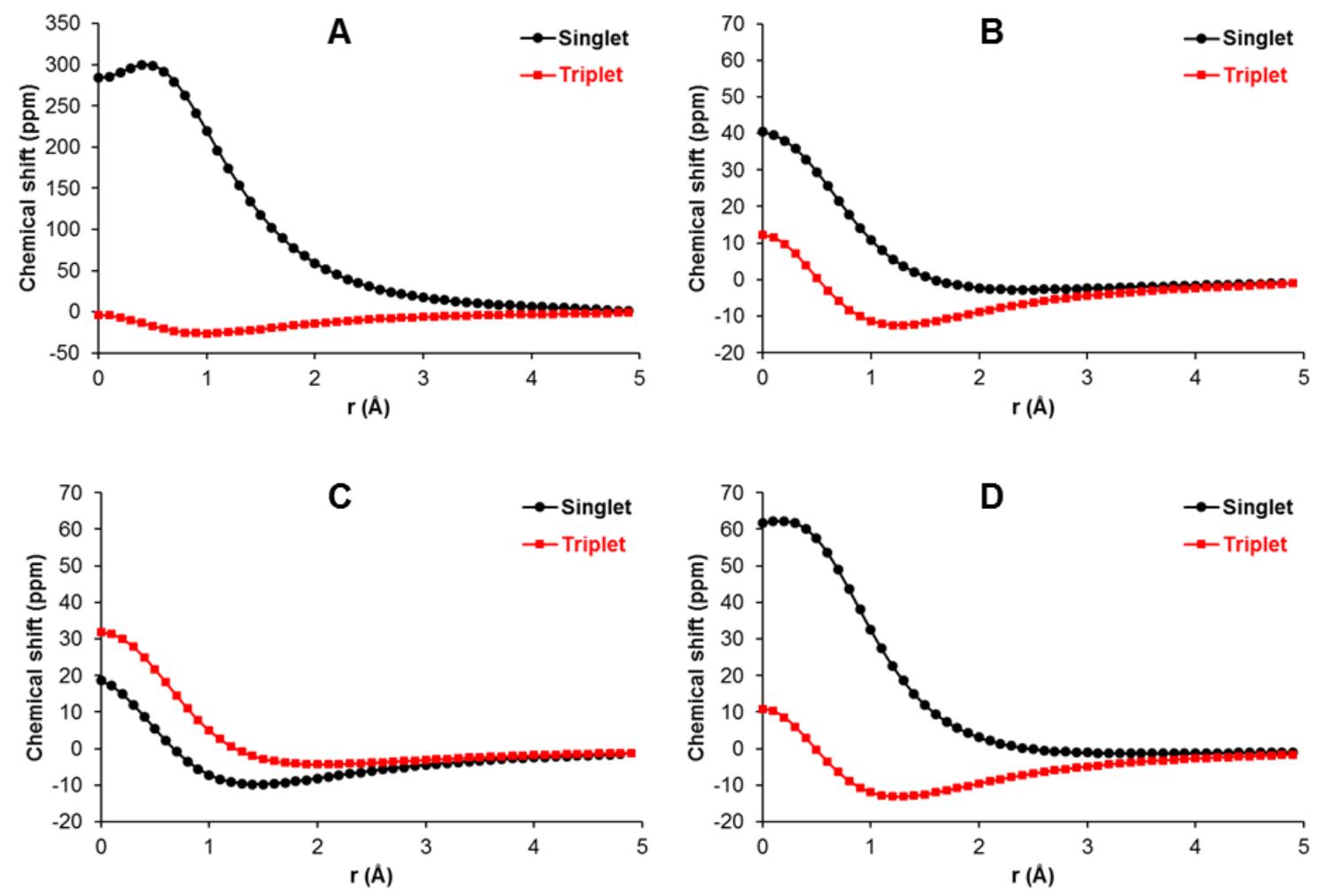

Figure 10: NICS-Z scans at GIAO/M06-2X/6-311+G(d,p) level for (A) $\mathbf{C p}^{+}$, (B) 1,3diaminoC $\mathbf{p}^{+},(\mathbf{C})$ fulvene $\mathbf{1}$ and $(\mathbf{D})$ fulvene $18\left(\mathrm{X}=\mathrm{CN}\right.$ and $\left.\mathrm{Y}=\mathrm{NH}_{2}\right)$ in the lowest singlet and triplet states.

Triplet ground state fulvenium dications: The synthesis of a fulvene resembling 18 is likely challenging. Moreover, full amino-substitution at the 5MR, which might be easier to achieve synthetically, leads to 2,3,4,5-tetraamino-6,6-dicyanofulvene (24) having an $E_{\mathrm{T}}$ at M06-2X/6-311+G(d,p) level of $10.4 \mathrm{kcal} / \mathrm{mol}$ and a $\Delta G_{\mathrm{T}}$ of $8.0 \mathrm{kcal} / \mathrm{mol}$, a result from steric congestion turning the four amino groups out of conjugation with the 5MR. A different approach to generate a fulvene with a $T_{0}$ state is needed. Here, we propose to 
increase the electron withdrawal by the EWGs (cyano groups) at the exocyclic position through protonation, and simultaneously utilize chloro substituents as EDGs at the 5MR. With this approach one can utilize protonation at the $\mathrm{N}$ atoms of the cyano groups of 2,3,4,5tetrachloro-6,6-dicyanofulvene $\left(\mathbf{1 5}(\mathbf{H})^{+}, \mathbf{1 5}(\mathbf{H}) 2^{2+}\right)$, a fulvene which is stable at ambient conditions and readily available. ${ }^{[17]}$

Although neutral 6,6-dicyanofulvenes (DCFs) have rather low-lying triplet states, ${ }^{[61,62]}$ the $\Delta G_{\mathrm{T}}$ for $\mathbf{1 5}(18.0 \mathrm{kcal} / \mathrm{mol})$ is still large, favoring the singlet state. Monoprotonation to give $\mathbf{1 5}(\mathbf{H})^{+}$lowers the gap to $8.3 \mathrm{kcal} / \mathrm{mol}$, and a triplet ground state is predicted for $\mathbf{1 5}(\mathbf{H}) 2^{2+}\left(\Delta G_{\mathrm{T}}=-2.0 \mathrm{kcal} / \mathrm{mol}\right.$ at $298 \mathrm{~K}$ with $\left.\mathrm{M} 06-2 \mathrm{X} / 6-311+\mathrm{G}(\mathrm{d}, \mathrm{p})\right)$. The $\mathrm{T}_{0}$ state of $\mathbf{1 5}(\mathbf{H}) \mathbf{2}^{\mathbf{2 +}}$ is also confirmed by $\mathrm{G} 4$ calculations $^{[36]}$ giving a $\Delta G_{\mathrm{T}}$ of $-2.2 \mathrm{kcal} / \mathrm{mol}$, and the same by CASPT2(14in14)/ANO-RCC-VTZP//M06-2X/6-311+G(d,p) $\left(\Delta G_{\mathrm{T}}=-3.4\right.$ $\mathrm{kcal} / \mathrm{mol}$, thermal corrections taken from M06-2X level).

The ACID plots show clear aromatic ring currents in the $\mathrm{T}_{0}$ state of $\mathbf{C p}^{+}$, while the Baird-aromaticities of $\mathbf{C p C l}_{5}{ }^{+}$and $\mathbf{1 5}(\mathbf{H})_{2}{ }^{2+}$ in their triplet states is less apparent (Figure 11). The ACID plot for ${ }^{3} \mathbf{C p C l}_{5}{ }^{+}$is consistent with that by Sander and co-workers, who calculated a NICS $(0)$ value of $-2.4 \mathrm{ppm}$, indicating moderate aromatic character. ${ }^{[63]} \mathrm{We}$ now performed a NICS scan to quantify the Baird-aromaticity of $\mathbf{1 5}(\mathbf{H}) 2^{2+}$ in its $\mathrm{T}_{0}$ state. The minimum value along the NICS-Z scan for the $\mathrm{T}_{0}$ state of $\mathbf{1 5}(\mathbf{H}) \mathbf{2}^{\mathbf{2 +}}(-13.8 \mathrm{ppm})$ is close to that of ${ }^{3} \mathbf{C p C l}^{+}$(-14.3 ppm), indicating that the two species are approximately equally Baird-aromatic. However, these NICS values are smaller than for ${ }^{3} \mathbf{C p}^{+}(-26.3 \mathrm{ppm})$, revealing that ${ }^{3} \mathbf{C p C l}^{+}$has a lower absolute Baird-aromaticity. 


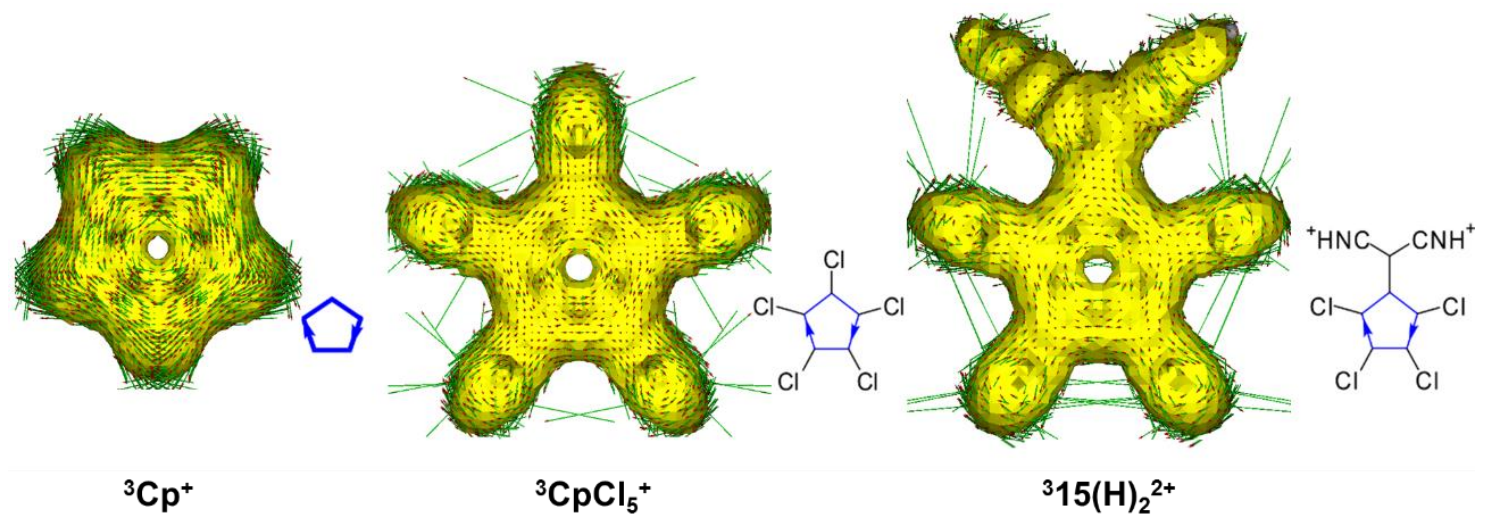

Figure 11. ACID plots showing the diatropic (aromatic, clockwise) ring current in the $\mathrm{T}_{0}$ states of $\mathbf{C p}^{+}, \mathbf{C p C l}^{+}$and $\mathbf{1 5}(\mathbf{H}) 2^{2+}$. Insets show qualitative circuits. ACID isosurface values of 0.030 . M06-2X/6-311+G(d,p) level is used.

Moreover, the electronic aromaticity index $\mathrm{FLU}^{[43 \mathrm{a}]}$ reveals that the $\mathrm{T}_{0}$ state of $\mathbf{1 5}(\mathbf{H})_{2}{ }^{\mathbf{2 +}}$ (0.0215) is equally aromatic as that of $\mathbf{C p C l}_{5}{ }^{+}(0.0216)$, while the FLU value of ${ }^{3} \mathbf{C p}^{+}$ (0.0084) is lower, again indicating that ${ }^{3} \mathbf{C p}^{+}$is more triplet state Baird-aromatic than ${ }^{3} \mathrm{CpCl}^{+}$. A similar observation is made when regarding the geometric aromaticity index HOMA (Figure 12). An analysis shows that ${ }^{3} \mathbf{C p C l}_{5}{ }^{+}$has extensive $\pi$-electron donation from the $\mathrm{Cl}$ lone pairs into the ring, as well as delocalization of the excess spin from the ring onto the $\mathrm{Cl}$ atoms, leading to a weakened cyclic (Baird-aromatic) $\pi$-electron delocalization within the 5MR (see Figure S4). Now, a high value of $\gamma$ for the five-membered ring of ${ }^{3} \mathbf{1 5}(\mathbf{H}) \mathbf{2}^{\mathbf{2 +}}$ (2.052) reveals dominating Baird-aromaticity of equal magnitude as that of ${ }^{3} \mathbf{C p C l}^{+}$(2.086). For comparison, the $\gamma$ of ${ }^{3} \mathbf{C p}^{+}$is 4.480 , a particularly large value as this molecule is an archetype of a Baird-aromatic species.

Finally, when comparing the neutral fulvene $\mathbf{1 8}$ with the fulvenium dication $\mathbf{1 5}(\mathbf{H})_{2}{ }^{2+}$, both with $T_{0}$ states, it is seen that the latter species displays a somewhat stronger Baird-aromaticity in the HOMA as well as the FLU data. NICS is also in agreement with 
HOMA and FLU in the sense that $\mathbf{1 5}\left(\mathbf{H}_{2}\right)^{\mathbf{2 +}}$ shows a slightly more negative value $(-13.8$ ppm) than 18 (-12.5 ppm), both in their $\mathrm{T}_{0}$ states.
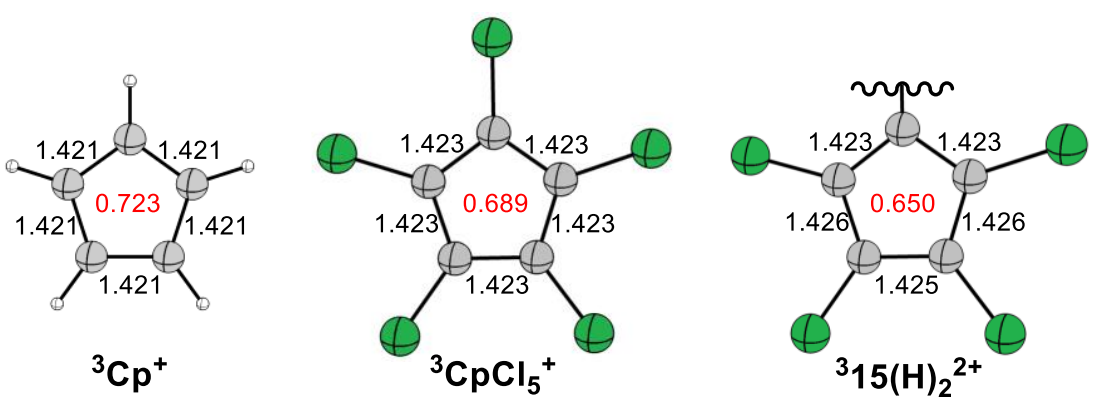

Figure 12. The calculated geometries of the $\mathrm{T}_{0}$ state $\mathbf{C p}^{+}, \mathbf{C p C l}^{+}$, and the $5 \mathrm{MR}$ of $\mathbf{1 5}(\mathbf{H})_{2}{ }^{2+}$ at M06-2X/6-311+G(d,p) level. HOMA values given in red inside the rings.

\section{Conclusions}

We have revealed strong correlations between the changes in aromaticity of fulvene derivatives when going from the $S_{0}$ to the $T_{1}$ state and the corresponding energy differences $\left(E_{\mathrm{T}}\right)$ of the fulvenes at their optimal planar geometries. Fulvenes are inherently aromatic chameleons compounds influenced by a zwitterionic Hückel-aromatic resonance structure in $\mathrm{S}_{0}$ and another zwitterionic Baird-aromatic resonance structure in $\mathrm{T}_{1}$ having opposite polarity to the one in the $\mathrm{S}_{0}$ state. The changes in aromaticity, and the relative stabilization of the $\mathrm{S}_{0} v s$. the $\mathrm{T}_{1}$ state (or vice versa), are connected to the ability of various substituents to enhance (reduce) Hückel-aromatic character in $S_{0}$ simultaneously as they reduce (enhance) the Baird-aromatic character in the $T_{1}$ state. Now, by utilizing the substituent effects on the singlet state Hückel-aromaticity and the triplet state Baird-aromaticity we can tailor fulvenes and fulvenium dications with very small and even inverted $E_{\mathrm{T}}$, i.e., species with triplet ground states. The results should open up for applications of fulvenes in areas where there is a need for compounds, all within one compound class, that span a range of different triplet state energies. 


\section{Acknowledgments}

First of all, we thank Drs. Raül Crespo, Kristine Kilså, Mari Carmen Piqueras, Sebastien Villaume and Jun Zhu for initial computations and fruitful discussions. We acknowledge the Carl Trygger Foundation for the postdoctoral fellowship of S.Y., the Wenner-Gren Foundation for postdoctoral fellowships of O.E.B. and H.T., the Swedish Research Council for financial support, and the National Supercomputer Center in Linköping, Sweden, for generous allotment of computer time. M.S. is grateful for financial support from the Spanish MINECO (project CTQ2017-85341-P), the Catalan DIUE (2017SGR39, XRQTC, and ICREA Academia 2014 Award), and the FEDER fund (UNGI10-4E-801).

Supporting Information Available: Listing of Cartesian coordinates, absolute energies, NICS(1), and HOMA data, plots of $E_{\mathrm{T}} v s . \Delta \mathrm{HOMA}_{\mathrm{ST}}, E_{\mathrm{T}} v s . \mathrm{HOMA}_{\mathrm{S} 0}$ as well as a discussion of the poor correlation between $E_{\mathrm{T}}$ and $\Delta \mathrm{HOMA}_{\mathrm{ST}}$, for the Z-substituted fulvenes. Supporting information for this article is given via a link at the end of the document.

\section{References}

[1] P. Preethalayam, K. S. Krishnan, S. Thulasi, S. S. Chand, J. Joseph, V. Nair, F. Jaroschik, K. V. Radhakrishnan, Chem. Rev. 2017, 117, 3930-3989.

[2] A. D. Finke, F. Diederich, Chem. Rec. 2014, 12, 19-30.

[3] P. A. Baron, R. D. Brown, F. R. Burden, P. J. Domaille, J. E. Kent, J. Mol. Spectrosc. 1972, 43, 401-410.

[4] P. Burk, J.-L. M. Abboud, I. A. Koppel, J. Phys. Chem. 1996, 100, 6992-6997. 
[5] A. P. Scott, I. Agranat, P. U. Biedermann, N. V. Riggs, L. Radom, J. Org. Chem. 1997, 62, 2026-2038.

[6] N. C. Baird, J. Am. Chem. Soc. 1972, 94, 4941-4948.

[7] V. Gogonea, P. v. R. Schleyer, P. R. Schreiner, Angew. Chem., Int. Ed. 1998, 37, 1945-1948.

[8] S. Villaume, H. F. Fogarty, H. Ottosson, ChemPhysChem 2008, 9, 257-264.

[9] (a) P. B. Karadakov, J. Phys. Chem. A 2008, 112, 7303-7309. (b) P. B. Karadakov, J. Phys. Chem. A 2008, 112, 12707-12713.

[10] F. Feixas, J. Vandenbussche, P. Bultinck, E. Matito, M. Solà, Phys. Chem. Chem. Phys. 2011, 12, 20690-20703.

[11] H. Ottosson, Nat. Chem. 2012, 4, 969-971.

[12] (a) M. Rosenberg, C. Dahlstrand, K. Kilså, H. Ottosson, Chem. Rev., 2014, 114, 5379-5425. (b) R. Papadakis, H. Ottosson, Chem. Soc. Rev. 2015, 44, 6472-6493.

[13] (a) Y. M. Sung, M-C. Yoon, J. M. Lim, H. Rath, K. Naoda, A. Osuka, D. Kim, Nat. Chem. 2015, 7, 418-422. (b) J. Oh, Y. M. Sung, Y. Hong, D. Kim, Acc. Chem. Res. 2018, 51, 1349-1358.

[14] H. Möllerstedt, M. C. Piqueras, R. Crespo, H. Ottosson, J. Am. Chem. Soc. 2004, $126,13938-13939$.

[15] a) T. L. Andrew, J. R. Cox, T. M. Swager, Org. Lett. 2010, 12, 5302-5305; b) C. Dahlstrand, K. Yamazaki, K. Kilså, H. Ottosson. J. Org. Chem. 2010, 75, 80608068; c) G. Jayamurugan, J.-P. Gisselbrecht, C. Boudon, F. Schoenebeck, W. B. Schweizer, B. Bernet, F. Diederich, Chem. Commun. 2011, 47, 4520-4522; d) A. D. Finke, O. Dumele, M. Zalibera, D. Confortin, P. Cias, G. Jayamurugan, J.-P. Gisselbrecht, C. Boudon, W. B. Schweizer, G. Gescheidt, F. Diederich, J. Am. Chem. Soc. 2012, 134, 18139-18146; e) A. D. Finke, B. O. Jahn, A. Saithalavi, C. Dahlstrand, D. Nauroozi, S. Haberland, J.-P. Gisselbrecht, C. Boudon, E. Mijangos, 
W. B. Schweizer, S. Ott, H. Ottosson, F. Diederich, Chem. Eur. J. 2015, 21, 81688176; f) N. Sadlej-Sosnowska, Struct Chem. 2018, 29, 23-31.

[16] B. T. Stępień, T. M. Krygowski, M. K. Cyrański, J. Org. Chem. 2002, 67, 59875992.

[17] H. Ottosson, K. Kilså, K. Chajara, M. C. Piqueras, R. Crespo, H. Kato, D. Muthas, Chem. Eur. J. 2007, 13, 6998-7005.

[18] K. Jorner, R. Emanuelsson, C. Dahlstrand. H. Tong, A. V. Denisova, H. Ottosson, Chem. Eur. J. 2014, 20, 9295-9303.

[19] M. Rosenberg, H. Ottosson, K. Kilså Phys. Chem. Chem. Phys. 2011, 13, 1291212919.

[20] R. Breslow, H. W. Chang, R. Hill, E. J. Wassermann, J. Am. Chem. Soc. 1967, 89, 1112-1119.

[21] M. Saunders, R. Berger, A. Jaffe, J. M. McBride, J. O’Neill, R. Breslow, J. M. Hoffman Jr., C. Perchonock, E. Wasserman, R. S. Hutton, V. J. Kuck, J. Am. Chem. Soc. 1973, 95, 3017-3018.

[22] (a) H. J. Wörner, F.Merkt, F. Angew. Chem. Int. Ed., 2006 45, 293-296. (b) H. J. Wörner, F.Merkt, F. J. Chem. Phys., 2007, 127, 034303.

[23] W. T. Borden, E. R. Davidson, Acc. Chem. Res., 1981, 14, 69-76.

[24] A. Soncini, P. W. Fowler, Chem. Phys. Lett., 2008, 450, 431-436.

[25] J. Zhu, K. An, P. v. R. Schleyer, Org. Lett., 2013, 15, 2442-2445.

[26] K. An, J. Zhu, Eur. J. Org. Chem., 2014, 2014, 2764-2769.

[27] F. De Proft, P. Geerlings, Phys. Chem. Chem. Phys., 2004, 6, 242-248.

[28] M. K. Cyrański, T. M. Krygowski, A. R. Katritzky, P. v. R. Schleyer, J. Org. Chem., 2002, 67, 1333-1338. 
[29] W.-Y. Cha, T. Kim, A. Ghosh, Z. Zhang, X.-S. Ke, R. Ali, V. M. Lynch, J. Jung, W. Kim, S. Lee, S. Fukuzumi, J. S. Park, J. L. Sessler, T. K. Chandrashekar, D. Kim, Nat. Chem. 2017, 9, 1243-1248.

[30] W. Zeng, H. Phan, T. S. Herng, T. Y. Gopalakrishna, N. Aratani, Z. Zeng, H. Yamada, J. Ding, J. Wu, Chem, 2017, 2, 11-12.

[31] E. Solel, S. Kozuch, J. Org. Chem. 2018, 83, 10826-10834.

[32] Y. Zhao, D. Truhlar, Theor. Chem. Acc. 2008, 120, 215-241.

[33] R. Krishnan, J. S. Binkley, R. Seeger, J. A. Pople, J. Chem. Phys. 1980, 72, 650654.

[34] R. A. Kendall, T. H. Dunning, Jr., R. J. Harrison J. Chem. Phys. 1992, 96, 67966806.

[35] M. J. Frisch, et al. Gaussian 16, revision B.01, Gaussian, Inc., Wallingford CT, 2016.

[36] L. A. Curtiss, P. C. Redfern, K. Raghavachari, J. Chem. Phys., 2007, 126, 84108.

[37] K. Andersson, P. A. Malmqvist, B. O. Roos, J. Chem. Phys. 1992, 96, 1218-1226.

[38] P. O. Widmark, B. J. Persson, B. O. Roos, Theor. Chim. Acta 1991, 79, 419-432.

[39] F. Aquilante, J. Autschbach, R. K. Carlson, L. F. Chibotaru, M. G. Delcey, L. De Vico, I. Fdez. Galván, N. Ferré, L. M. Frutos, L. Gagliardi, M. Garavelli, A. Giussani, C. E. Hoyer, G. Li Manni, H. Lischka, D. Ma, P. Å. Malmqvist, T. Müller, A. Nenov, M. Olivucci, T. B. Pedersen, D. Peng, F. Plasser, B. Pritchard, M. Reiher, I. Rivalta, I. Schapiro, J. Segarra-Martí, M. Stenrup, D. G. Truhlar, L. Ungur, A. Valentini, S. Vancoillie, V. Veryazov, V. P. Vysotskiy, O. Weingart, F. Zapata, R. Lindh, MOLCAS 8: New Capabilities for Multiconfigurational Quantum Chemical Calculations across the Periodic Table J. Comput. Chem., 2016, 37, 506-541. 
[40] V. I. Minkin, M. N. Glukhovtsev, B. Y. Simkin, Aromaticity and Antiaromaticity Electronic and Structural Aspects; J. Wiley \&Sons: New York, 1994.

[41] P. v. R. Schleyer, Guest Editor. Thematic issue of Chem. Rev. 2001, 101, 11151118.

[42] B. T. Stępień, M. K. Cyrański, T. M. Krygowski, Chem. Phys. Lett. 2001, 350, $537-542$.

[43] P. v. R. Schleyer, C. Maerker, A. Dransfield, H. Jiao, N. J. R. v. E. Hommes, J. Am. Chem. Soc. 1996, 118, 6317-6318.

[44] P. v. R. Schleyer, H. Jiao, N. J. R. v. E. Hommes, V. G. Malkin, O. L. Malkina, J. Am. Chem. Soc. 1997, 119, 12669-12670.

[45] R. Y. West, J. J. Buffy, M. Haaf, T. Müller, B. Gehrhus, M. F. Lappert, Y. Apeloig, J. Am. Chem. Soc. 1998, 120, 1639-1640.

[46] Z. Chen, C. S. Wannere, C. Corminboeuf, R. Puchta, P. v. R. Schleyer, Chem. Rev. 2005, 105, 3842-3888.

[47] T. M. Krygowski, J. Chem. Inf. Comput. Sci. 1993, 33, 70-78.

[48] T. M. Krygowski, M. K. Cyrański, Tetrahedron 1996, 52, 1713-1722.

[49] T. M. Krygowski, M. K. Cyrański, Chem. Rev. 2001, 101, 1385-1420.

[50] (a) E. Matito, M. Duran, M. Solà, J. Chem. Phys. 2005, 122, 014109. (b) Erratum: E. Matito, M. Duran, M. Solà, J. Chem. Phys. 2006, 125, 059901.

[51] (a) R. Herges, D. Geuenich, J. Phys. Chem. A, 2001, 105, 3214-3220. (b) D.

Geuenich, K. Hess, F. Köhler, R. Herges, Chem. Rev. 2005, 105, 3758-3772.

[52] K. Wolinski, J. F. Hinton, P. Pulay, J. Am. Chem. Soc. 1990, 112, 8251-8260.

[53] H. Fallah-Bagher-Shaidaei, C.S. Wannere, C. Corminboeuf, R. Puchta, P.v.R. Schleyer, Org. Lett. 2006, 8, 863-866.

[54] A. Stanger, J. Org. Chem. 2006, 71, 883-893.

[55] A. Stanger, Chem. Eur. J. 2006, 12, 2745-2751. 
[56] (a) F. Feixas, E. Matito, J. Poater, M. Solà, Chem. Soc. Rev. 2015, 44, 6434-6451.

(b) X. Fradera, M. A. Austen, R. F. W. Bader, J. Phys. Chem. A 1999, 103, 304-

314. (c) X. Fradera, J. Poater, S. Simon, M. Duran, M. Solà, Theor. Chem. Acc. 2002, 108, 214-224.

[57] Matito, E. ESI-3D: Electron Sharing Indexes Program for 3D Molecular Space Partitioning. http://iqc.udg.es/ eduard/ESI, Institute of Computational Chemistry and Catalysis, Girona, Catalonia, Spain, 2014.

[58] Keith A. AIMall (v. 14.11.23). Overland Park KS, USA: TK Gristmill Software (aim.tkgristmill.com); 2014.

[59] K. Jorner, F. Feixas, R. Ayub, R. Lindh, M. Solà, H. Ottosson, Chem. Eur. J. 2016, 22, 2793-2800.

[60] For $\mathbf{1 8}$ and 1,3-diamino $\mathbf{C p}^{+}$in their singlet states the $\mathrm{T}_{1}$-diagnostic values from $\operatorname{CCSD}(\mathrm{T}) / / \mathrm{M} 06-2 \mathrm{X}$ calculations are 0.015 and 0.017 , respectively, which are below the threshold of 0.02 revealing that a single-reference method suffices.

[61] P. J. Stephens, F. J. Devlin, C. F. Chabalowski, M. J. Frisch, J. Phys. Chem., 1994, 98, 11623-11627.

[62] Y. Zhao, D. G. Truhlar, Acc. Chem. Res., 2008, 41, 157-167.

[63] P. Costa, I. Trosien, J. Mieres-Perez, W. Sander, J. Am. Chem. Soc., 2017, 139, 13024-13130. 